\title{
Evaluation of the catalytic activity of oxide nanoparticles synthesized by the polymeric precursor method on biodiesel production
}

\author{
Gabriela Santilli do Nascimento \\ Departamento de Química, Universidade Federal de São Carlos, CEP 13.565-905, São Carlos, São Paulo, Brazil \\ Giovanni Pimenta Mambrini \\ Departamento de Química, Universidade Federal de Viçosa, s/n - Campus Universitário, CEP 36570-000, Viçosa, \\ Minas Gerais, Brazil \\ Elaine Cristina Paris \\ Embrapa Instrumentação, CEP 13560-970, São Carlos, São Paulo, Brazil \\ Juliano Aurelio Peres \\ Departamento de Química, Universidade Federal de São Carlos, CEP 13.565-905, São Carlos, São Paulo, Brazil \\ Luis Alberto Colnago and Caue Ribeiro ${ }^{\text {a) }}$ \\ Embrapa Instrumentação, CEP 13560-970, São Carlos, São Paulo, Brazil
}

(Received 28 June 2012; accepted 19 September 2012)

\begin{abstract}
This paper shows a comparison between different nanostructured oxides, obtained by polymeric precursor method, regarding their activity for biodiesel conversion from oil-methanol mixtures. The basicity/acidity and surface area (SA) of the oxides were taken in account to analyze the catalytic activity in the transesterification reaction. The temperature dependence for the heterogeneous catalysts was analyzed, where only $\mathrm{CaO}$ showed activities at $70{ }^{\circ} \mathrm{C}(\sim 98 \%$ of conversion), while the other oxides, $\mathrm{SnO}_{2}, \mathrm{ZnO}, \mathrm{TiO}_{2}, \mathrm{CaTiO}_{3}$, were observed active only at $150{ }^{\circ} \mathrm{C}$ for the reaction parameters adopted. The results revealed that the highest activity observed is not associated to SA only but mainly with the surface basicity. This suggest that, for oxides synthesized by the polymeric precursor method, the surface basicity surpasses the particle size effects in catalysis in a way to promote the transesterification reaction.
\end{abstract}

\section{INTRODUCTION}

Biodiesel is a promising alternative fuel since it can be used in diesel engines without any modification. Furthermore, biodiesel shows interesting properties such as biodegradability, nontoxicity, and renewability. This biofuel is produced by the transesterification reaction of vegetable oils with alcohols, and the most common method to its production is the use of homogeneous catalysts, such as sodium ethoxide or methoxide. ${ }^{1}$ However, the removal of these catalysts from the final products is not easy because, in case of water presence, soapy fractions are formed as a competitive reaction, which emulsifies the final products with unreacted fractions. The separation in that cases is a very complex process, increasing the cost of the biodiesel processing. ${ }^{2}$ Then, compared with the commonly applied homogeneous catalysts, heterogeneous catalysts are much more easily separated from the reaction medium, avoid the emulsification, and may be recycled for several runs, implying also lower corrosion in production equipments. ${ }^{3-5}$ However, the activities of the heterogeneous catalysts are

\footnotetext{
a) Address all correspondence to this author.

e-mail: caue@cnpdia.embrapa.br

DOI: $10.1557 / \mathrm{jmr} .2012 .349$
}

generally lower than that of a homogeneous catalyst, such as $\mathrm{KOH}^{6}{ }^{6}$ In this way, a great research effort has been performed to obtain an effective heterogeneous catalyst. ${ }^{7-9}$

Currently, several types of heterogeneous nanocatalysts are explored for the formation of biodiesel, such as ceramic oxides, ${ }^{5,6,8}$ alkali carbonates, ${ }^{10}$ and several other compounds of alkali metals supported on silica or zeolites. $^{11,12} \mathrm{CaO}$ is the most studied heterogeneous catalyst, due to its high basicity, which leads to a more prominent activity for biodiesel transesterification. ${ }^{7,10,13}$ Acid catalysts may also have adequate characteristics since the reaction may be catalyzed by both basic and acid sites. ${ }^{2,9}$ However, many researches showed that there is a relationship between the transesterification rate and the intrinsic basicity of the catalyst,${ }^{14}$ indicating that acid catalysts present low activity in transesterification of vegetable oils to biodiesel if compared with basic catalysts in the same reaction conditions. ${ }^{2,8,14}$ According to Di Serio et al., ${ }^{2}$ to improve the reaction rate using acid catalysts, it is necessary to increase the reaction time and temperature.

Several nanocrystalline metal oxides with potential application, such as $\mathrm{TiO}_{2},{ }^{5} \mathrm{ZnO},{ }^{15} \mathrm{SnO}_{2},{ }^{9}$ and $\mathrm{CaTiO}_{3}{ }^{6}$ have been studied as catalysts for the biodiesel production. Nevertheless, there are few works comparing the effectiveness of the transesterification reaction, regarding the 
acidity-basicity of these catalysts. ${ }^{2,6,8}$ In this scenario, the choice of the synthesis method is essential for the quality of heterogeneous catalysts due to influence in multiple properties and especially on the surface of the material. Different methods are used to obtain nanoparticles, such as nonaqueous synthesis, ${ }^{16}$ coprecipitation, ${ }^{17,18}$ sol-gel, ${ }^{19}$ and the polymeric precursor method. ${ }^{20-22}$ The last one offers several advantages to produce different materials, including single metal to multication oxides, such as direct and accurate stoichiometric control, homogeneity, and uniform multicomponent mixing on a molecular scale. ${ }^{23}$

In this way, the present work was aimed to compare different metal oxide nanoparticles obtained by the polymeric precursor method and correlate their activities against the transesterification of corn oil with methanol.

\section{EXPERIMENTS}

\section{A. Synthesis of catalytic powders}

$\mathrm{ZnO}, \mathrm{SnO}_{2}, \mathrm{CaO}$, and $\mathrm{CaTiO}_{3}$ nanoparticles were obtained by the polymeric precursor method. ${ }^{24}$ The choice of this method was based on its efficacy in the synthesis of multication oxides. ${ }^{25,26}$ As reactant precursors for the $\mathrm{ZnO}$, $\mathrm{SnO}_{2}, \mathrm{CaO}, \mathrm{CaTiO}_{3}$, and $\mathrm{TiO}_{2}$ syntheses, zinc chloride $\mathrm{ZnCl}_{2}$ (99.3\% purity; Mallinckrodt, Hazelwood, MO), tin chloride $\mathrm{SnCl}_{2} \cdot 2 \mathrm{H}_{2} \mathrm{O}$ (98\% purity; Synth, Brazil), calcium carbonate $\mathrm{CaCO}_{3}$ (99\% purity; Synth, Brazil), titanium(IV) isopropoxide [ $\mathrm{Ti}\left(\mathrm{OC}_{3} \mathrm{H}_{7}\right)_{4}, 97 \%$ purity; Aldrich, Brazil] were used. The anhydrous citric acid $\left(\mathrm{C}_{6} \mathrm{H}_{8} \mathrm{O}_{7}, 99.5 \%\right.$ purity; Nuclear, Brazil) and ethylene glycol $\left(\mathrm{C}_{2} \mathrm{H}_{6} \mathrm{O}_{2}, 99 \%\right.$ purity; Synth, Brazil) were used to promote the complexation and polyesterification reactions, respectively. An aqueous solution of each metallic citrate was prepared for each oxide.

In a typical procedure, citric acid is dissolved in distilled water under constant stirring and heated to approximately $90{ }^{\circ} \mathrm{C}$. In this solution, the corresponding cation source for each oxide is added, according to molar relation 3:1 citric acid:metallic cation. After the total cation complexation, ethylene glycol is added to the solution in a mass ratio of 60 citric acid:40 ethylene glycol, to polymerize the final solution. Stirring and temperature are maintained constant during the process. Thus, a precursor solution containing the metallic cations is obtained. After that, the solution is annealed in a conventional furnace at $350{ }^{\circ} \mathrm{C}$ for $2 \mathrm{~h}$ to favor the polymer prepyrolysis. The resultant materials are deagglomerated and calcined at different temperatures and periods, to promote the oxidation and complete elimination of the residual organic material.

In this way, the respective oxide precursors were heat treated at $800{ }^{\circ} \mathrm{C}$ for $2 \mathrm{~h}$ to $\mathrm{SnO}_{2}$ and $\mathrm{ZnO}, 450{ }^{\circ} \mathrm{C}$ for $1 \mathrm{~h}$ to $\mathrm{TiO}_{2}, 700{ }^{\circ} \mathrm{C}$ for $2 \mathrm{~h}$ to $\mathrm{CaTiO}_{3}$, and $1000{ }^{\circ} \mathrm{C}$ for $2 \mathrm{~h}$ to $\mathrm{CaO}$ with the view to obtain a crystalline and single phase for each oxide. The experimental conditions for each were adjusted to guarantee a final crystalline material, with clean surfaces.

\section{B. Characterization}

The synthesized oxides, $\mathrm{SnO}_{2}, \mathrm{ZnO}, \mathrm{TiO}_{2}, \mathrm{CaTiO}_{3}$, and $\mathrm{CaO}$, were characterized by $\mathrm{x}$-ray diffraction, using a Shimadzu XRD-6000 diffractometer (Japan) at $30 \mathrm{kV}$ and $30 \mathrm{~mA}$ with $\mathrm{Cu} \mathrm{K}_{\alpha}$ radiation of $0.154 \mathrm{~nm}$. The samples were scanned from $20^{\circ}$ to $70^{\circ}$ with a scan velocity of $1 \% \mathrm{~min}$. The specific surface areas (SAs) were obtained by nitrogen physisorption method [Micromeritics ASAP 2000, Norcross, GA using the Brauner-Emmett-Teller (BET) isotherm], where the samples were subjected to a pretreatment in vacuum at $90{ }^{\circ} \mathrm{C}$ to achieve degassing pressure below $6 \mu \mathrm{mHg}$ before obtaining the adsorption isotherms. Zeta potential measurements were used to infer the surface basicity/acidity of the synthesized oxides nanoparticles (Zetaplus, Nano-ZS; Malvern Instruments, UK). To ensure the adequate evaluation of surface basicity/acidity, an aliquot of equal mass of each oxide was stirred during $24 \mathrm{~h}$ in dark on $1 \mathrm{~mL}$ of methanol at room temperature $\left(25^{\circ} \mathrm{C}\right)$, and the final Zeta potential was measured on the solution, without oxide separation.

Inductively coupled plasma optical emission spectrometer (ICP-OES) with radial view (Vista RL; Varian, Mulgrave, Australia) and $1.3 \mathrm{~kW}$ was used to determine the oxide solubility in methanol. Microstructural characterization was performed by field emission scanning electron microscopy (FEG-SEM, Zeiss Supra TM 35, Germany) operating in $2 \mathrm{kV}$.

\section{Catalytic activity test}

The catalytic activity of the oxides was evaluated using commercial corn oil and methanol $(99.8 \%$ purity; Aldrich) with a catalyst:oil mass ratio of 5\%. In summary, the catalyst was dispersed in methanol followed by the addition of corn oil in a alcohol:oil molar ratio of 30:1. The suspension was then heated at 70 or $150{ }^{\circ} \mathrm{C}$ for $2 \mathrm{~h}$, using sealed tubes to avoid methanol evaporation. At the end of each test, the methyl ester phase was separated by centrifugation. The resultant material was analyzed by ${ }^{1} \mathrm{H}$ nuclear magnetic resonance $\left({ }^{1} \mathrm{H}\right.$ NMR) spectroscopy to quantify the biodiesel produced. The analyses were performed in a Varian Inova 400 NMR spectrometer (Palo Alto, CA), with magnetic field of $9.4 \mathrm{~T}(400 \mathrm{MHz})$ for ${ }^{1} \mathrm{H}$ resonance frequency. All spectra were obtained by accumulating 32 spectra with $90^{\circ}$ flip angle, $2.5 \mathrm{~s}$ of acquisition time, and $15 \mathrm{~s}$ of delay time. ${ }^{27}$ An aliquot of $10 \mu \mathrm{L}$ sample dissolved in $500 \mu \mathrm{L}$ of deuterated chloroform and tetramethylsilane was used as internal standard.

\section{RESULTS AND DISCUSSION}

Figure 1 shows FEG-SEM images of the as-synthesized materials annealed at $800{ }^{\circ} \mathrm{C} / 2 \mathrm{~h}$ for $\mathrm{SnO}_{2}$ and $\mathrm{ZnO}$, $450{ }^{\circ} \mathrm{C} / 1 \mathrm{~h}$ for $\mathrm{TiO}_{2}, 700{ }^{\circ} \mathrm{C} / 2 \mathrm{~h}$ for $\mathrm{CaTiO}_{3}$, and $1000{ }^{\circ} \mathrm{C} / 2 \mathrm{~h}$ for $\mathrm{CaO}$. As observed, the polymeric 

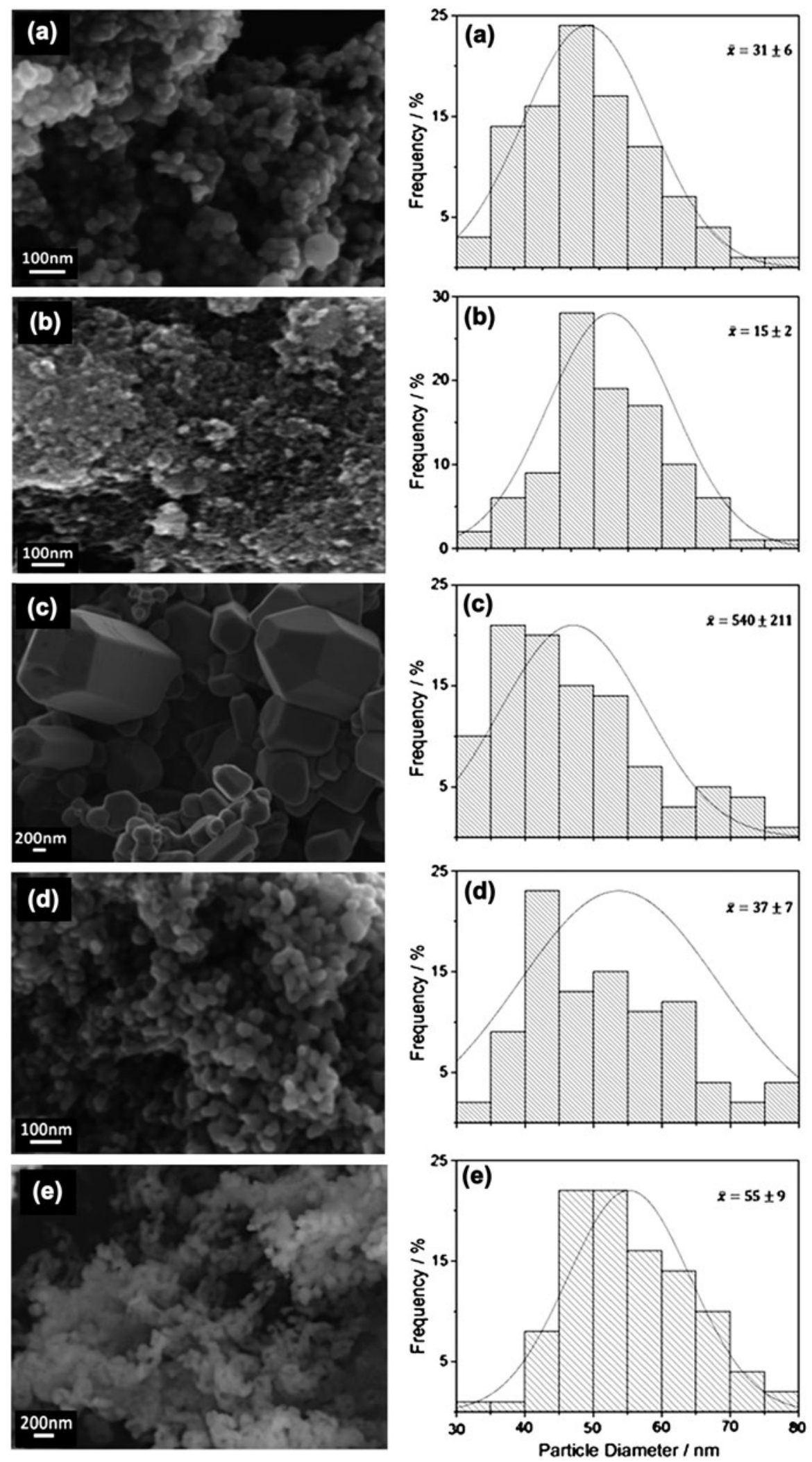

FIG. 1. FEG-SEM microscopy and the particle size diameter of oxides synthesized at different temperatures and times: (a) $\mathrm{SnO} \mathrm{O}_{2}$ at $800{ }^{\circ} \mathrm{C}$ for $2 \mathrm{~h}$, (b) $\mathrm{TiO}_{2}$ at $450{ }^{\circ} \mathrm{C}$ for $1 \mathrm{~h}$, (c) $\mathrm{ZnO}$ at $800{ }^{\circ} \mathrm{C}$ for $2 \mathrm{~h}$, (d) $\mathrm{CaTiO}_{3}$ at $700{ }^{\circ} \mathrm{C}$ for $2 \mathrm{~h}$, and (e) $\mathrm{CaO}$ at $1000{ }^{\circ} \mathrm{C}$ for $2 \mathrm{~h}$. 
precursor method resulted in very similar morphologies for all the powders, except for $\mathrm{ZnO}$ nanoparticles. This sample shows a faceted behavior in Fig. 1(c), typical of wurtzite hexagonal structure, which is observed in several other synthesis procedures, as reported by Umar et al. ${ }^{28}$ $\mathrm{ZnO}$ phase presented the largest particle size with an average size of $540 \mathrm{~nm}$, while other materials showed values around $15-55 \mathrm{~nm}$, which are confirmed by direct measurement in FEG-SEM images. A comparative analysis of all synthesized oxides indicates that the $\mathrm{ZnO}$ nanoparticles present a low control of the particle size and distribution by this synthetic method. This behavior may be related to the low crystallization temperature of the $\mathrm{ZnO}$ phase, when compared to the other oxides. Due to this, in this material, a presintering process is possible at this temperature, which will involve the particle growth and formation of larger particles by diffusion. Comparing to $\mathrm{SnO}_{2}$, this oxide also presents low crystallization temperature; however, this oxide does not sinter without dopants, as is the case of the present work. Regarding $\mathrm{TiO}_{2}$, at that annealing temperature, the transition from anatase to rutile phases may retain the grain growth. Finally, for $\mathrm{CaO}$ and $\mathrm{CaTiO}_{3}$, it is important to remember that both oxides are formed from the dehydration of $\mathrm{Ca}(\mathrm{OH})_{2}$, which means that this process may also retain the grain growth.

As observed by Table I, the measured SAs showed different values for each sample. $\mathrm{TiO}_{2}$ nanoparticles showed SA around $41 \mathrm{~m}^{2} / \mathrm{g}$, a larger value comparable to other papers in literature ${ }^{8,29,30}$ for this material. Despite the similar particle sizes, $\mathrm{SnO}_{2}, \mathrm{CaO}$, and $\mathrm{CaTiO}_{3}$ nanoparticles showed lower values than $\mathrm{TiO}_{2}$, which may be explained by the different agglomeration behaviors during calcinations, distinct density of materials, and dissimilar pore size distribution. The smallest SA value for the $\mathrm{ZnO}\left(3.7 \mathrm{~m}^{2} / \mathrm{g}\right)$ is directly associated to the largest particle sizes, as previously discussed. It is important to observe the powder agglomeration, which is characteristic of the synthetic method. This is highly undesirable for catalytic purposes since it can suppress SA for the heterogeneous process. However, the equilibrium electrode potential measured at room temperature in methanol medium, for each system analyzed, showed a sequence correlated to

TABLE I. Physicochemical properties of the metal oxides and methanol.

\begin{tabular}{lccccc}
\hline \hline Catalyst & Cation & Anion & $\mathrm{SA}\left(\mathrm{m}^{2} / \mathrm{g}\right)$ & $\begin{array}{c}\text { Zeta potential } \\
(\mathrm{mV})\end{array}$ & $\begin{array}{c}\text { Metal ion } \\
\text { solubility }(\mathrm{mg} / \mathrm{L})\end{array}$ \\
\hline $\mathrm{SnO}_{2}$ & $\mathrm{Sn}^{4+}$ & $\mathrm{O}^{2-}$ & 10.1 & -39.8 & 0.16 \\
$\mathrm{TiO}_{2}$ & $\mathrm{Ti}^{4+}$ & $\mathrm{O}^{2-}$ & 41.2 & -12.9 & 0.05 \\
$\mathrm{ZnO}$ & $\mathrm{Zn}^{2+}$ & $\mathrm{O}^{2-}$ & 3.7 & -4.0 & 0.22 \\
$\mathrm{CaTiO}_{3}$ & $\mathrm{Ca}^{2+}$ & $\mathrm{TiO}_{3}^{2-}$ & 27.3 & 24.9 & $0.04(\mathrm{Ca})$ \\
$\mathrm{CaO}$ & $\mathrm{Ca}^{2+}$ & $\mathrm{O}^{2-}$ & 18.3 & 45.6 & $0.06(\mathrm{Ti})$ \\
\hline \hline
\end{tabular}

the expected basicity of the oxides, from $\mathrm{CaO}$ (highest) to $\mathrm{SnO}_{2}$ (lowest), despite the different SAs. The basicity scale is an important reference for the catalytic activity in methanol since it is well consolidated in literature ${ }^{31}$ the reaction between basic sites and methanol. This reaction generates methoxide groups, which are referred as the real reactant in biodiesel formation. ${ }^{31}$

The phase formation of the synthesized powders was evaluated by x-ray diffraction (XRD), as shown in Fig. 2, confirming the desired phases in all the cases. $\mathrm{CaO}$ and $\mathrm{CaTiO}_{3}$ nanoparticles showed some small contamination of $\mathrm{CaCO}_{3}$ phase, resulted from direct reaction with the environment. $^{4,12}$

The catalytic performance of the oxides against biodiesel formation was monitored by NMR spectroscopy. Figure 3 shows typical spectra of corn oil (bottom) and its biodiesel (top). The signal between 4.05 and $4.35 \mathrm{ppm}$ in the oil spectra and inset is related to the glycerol moiety of

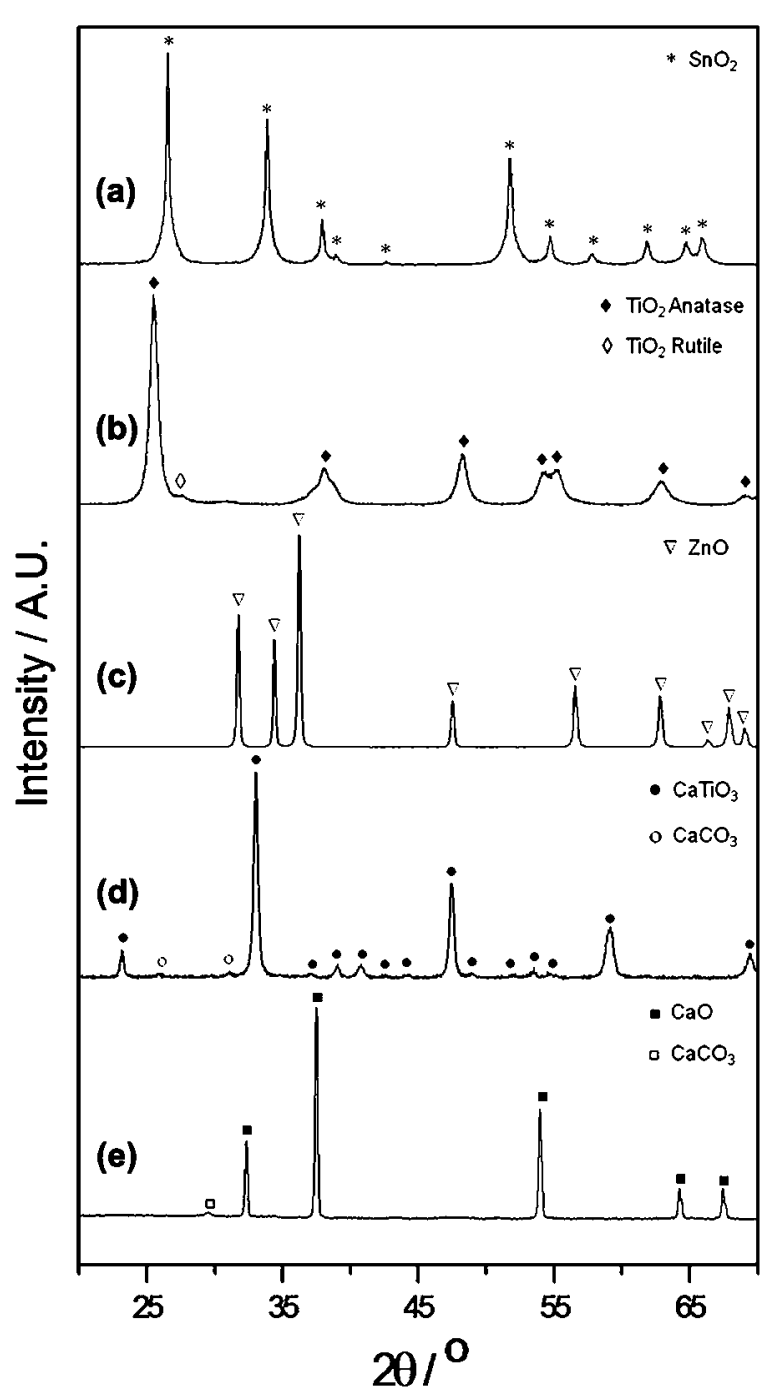

FIG. 2. XRD patterns of oxides synthesized at different temperatures and times: (a) $\mathrm{SnO}_{2}$, (b) $\mathrm{TiO}_{2}$, (c) $\mathrm{ZnO}$, (d) $\mathrm{CaTiO}_{3}$, and (e) $\mathrm{CaO}$. 


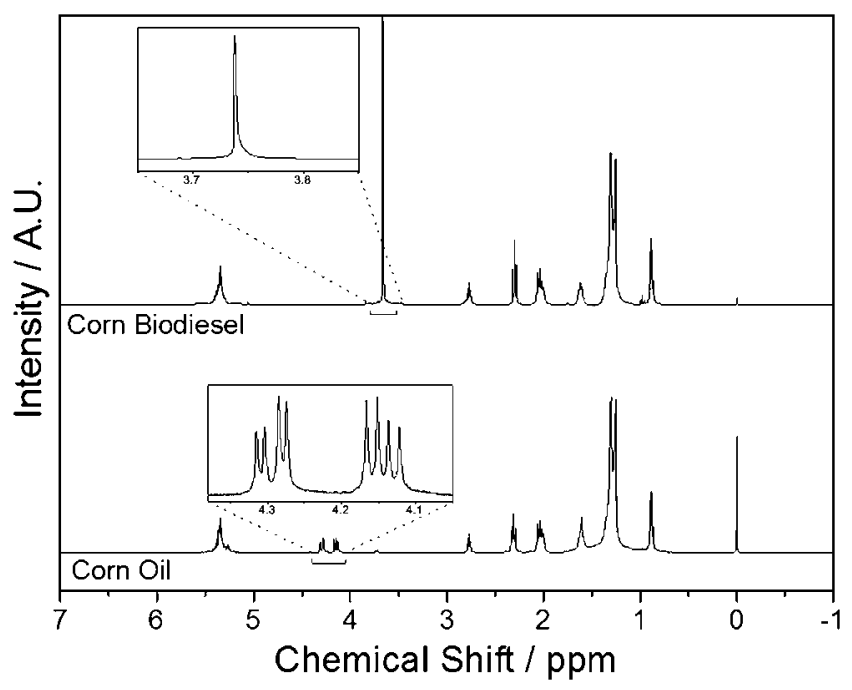

FIG. 3. ${ }^{1} \mathrm{H}$ NMR spectra of the corn oil (bottom) and corn biodiesel (top). The insets show the glycerol and methoxy groups used to monitor the transesterification reaction.

the triacylglycerides and disappears during the biodiesel formation. During the reaction, a singlet at $3.67 \mathrm{ppm}$ related to the methoxy group of the fatty acid methyl ester (biodiesel) is observed and used to monitor the biodiesel yield. ${ }^{27,32}$ Figure 4 shows the biodiesel yield after $2 \mathrm{~h}$ for each system. Except for $\mathrm{CaO}$, the conversions at $70{ }^{\circ} \mathrm{C}$ were negligible, and the materials could not be reported as catalysts for this reaction. The activity observed for $\mathrm{CaO}$ is similar to that observed in other papers ${ }^{4,7}$ and comparable to the expected activity for other homogeneous catalysts, such as $\mathrm{NaOH}$ and $\mathrm{KOH} .{ }^{33-35}$

However, an adequate comparison at higher reaction temperature may reveal details about the surface activity of each oxide. The essays at $150{ }^{\circ} \mathrm{C}$ for $2 \mathrm{~h}$, using the same reactants in a sealed system, showed catalytic activity for all the samples, except for $\mathrm{SnO}_{2}$. Since $\mathrm{CaO}$ was verified as very effective at $70{ }^{\circ} \mathrm{C}$, its evaluation at $150{ }^{\circ} \mathrm{C}$ was not necessary, but it was opted to compare with commercial calcium hydroxide $\mathrm{Ca}(\mathrm{OH})_{2}$ (P.A.-ACS; Synth, Brazil). It is important to notice that this material was observed as inactive at $70{ }^{\circ} \mathrm{C}$, as shown in Fig. 4.

In fact, the expected surface characteristic, regarding basicity for those materials, is $\mathrm{SnO}_{2}<\mathrm{TiO}_{2}<\mathrm{ZnO}<$ $\mathrm{CaTiO}_{3}<\mathrm{Ca}(\mathrm{OH})_{2}<\mathrm{CaO}$. This behavior was the same observed for the catalytic activity at $150{ }^{\circ} \mathrm{C}$. Furthermore, it is important to notice those data in the function of the SA measurements: despite $\mathrm{ZnO}$ showed the lowest value, its activity was higher than the other oxides, indicating that the surface basicity is more important than SA, in case of the experimental conditions of this present work. It is worth mentioning the amphoteric feature of $\mathrm{ZnO}$ materials. ${ }^{36}$ This observation confirms that the reaction shows the higher activity on basic surfaces, as reported in literature. However, a very important aspect is noticed: $\mathrm{TiO}_{2}$ and $\mathrm{CaTiO}_{3}$

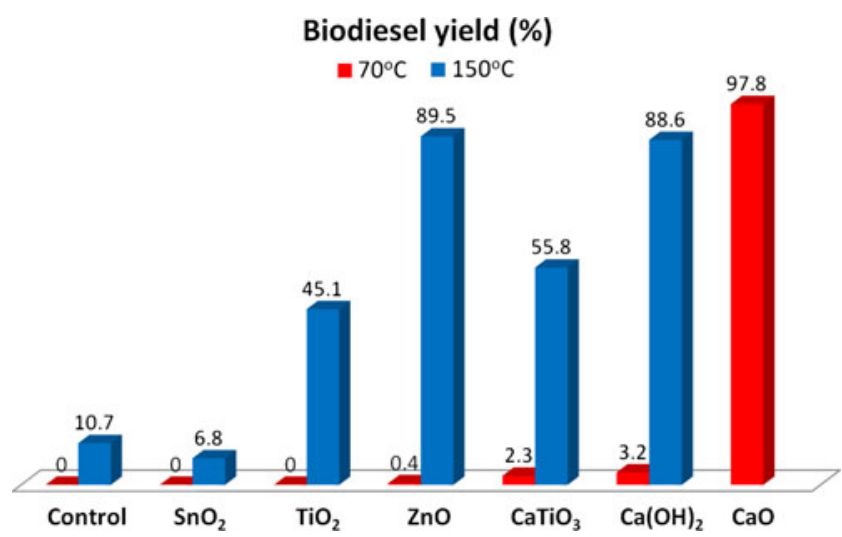

FIG. 4. Yield to biodiesel using the metal oxides as catalysts at 70 and $150{ }^{\circ} \mathrm{C}$ for $2 \mathrm{~h}$. Control refers to the reaction of methanol:oil without catalyst.

showed significant activities (around $45-50 \%$ conversions) after $2 \mathrm{~h}$ at $150^{\circ} \mathrm{C}$, which are good results compared to the literature. ${ }^{6,8}$ In a similar paper, Kawashima et al. ${ }^{6}$ reported activities around $79 \%$ after $10 \mathrm{~h}$ at $60{ }^{\circ} \mathrm{C}$, with mass ratio of $10 \%$ to catalyst/oil and 6:1 molar ratio of methanol:oil for $\mathrm{CaTiO}_{3}\left(\mathrm{SA}-4.9 \mathrm{~m}^{2} / \mathrm{g}\right)$. Granados et al. ${ }^{4}$ observed for $\mathrm{TiO}_{2}$ nanoparticles $\left(\mathrm{SA}-10.9 \mathrm{~m}^{2} / \mathrm{g}\right.$ ) activities around $10 \%$ after $10 \mathrm{~min}$ at $200{ }^{\circ} \mathrm{C}$, with mass ratio of $1 \%$ to catalyst/oil and 40:1 molar ratio of methanol:oil. Concerning $\mathrm{CaTiO}_{3}$, the authors studied longer periods at lower temperature and higher catalyst concentrations than in this paper, to improve the activity. In $\mathrm{TiO}_{2}$, although the authors applied higher temperatures and longer times, the lower catalyst concentration influenced the final results. In this way, it is possible to verify that all synthesis parameters influence significantly the biodiesel conversion.

It is worth mentioning the difference observed between $\mathrm{ZnO}$ and $\mathrm{CaTiO}_{3}$. Despite one may expect better conversion values for this last oxide, due to its presumably higher surface basicity, its lower activity may be related to the larger anion involved in this reaction, $\mathrm{TiO}_{3}{ }^{2-}$. In fact, literature claims that the active site for heterogeneous basic catalysis is the anion site ${ }^{37,38}$ which, in this case, would be less active, since the $\mathrm{Ti}^{4+}$ into its structure may reduce the electronegativity of the final site. Anyway, this is an aspect still open, which is under investigation yet.

A last point that arises from this comparison is the real heterogeneous feature of analyzed oxides. The solubility concentration values of the residual metal ions in methanol obtained from ICP-OES measurements are depicted in Table I. These results indicate that all the oxides are poorly soluble in the reaction conditions, except $\mathrm{CaO}$. For this oxide, after annealing at $70{ }^{\circ} \mathrm{C}$ during $2 \mathrm{~h}$, the analysis revealed it as soluble, compared to the other oxides, despite with very low dissolved values, which suggests that homogenous catalysis is not occurring or is not the main mechanism in the reaction. However, this fact needs to be taken in account since this small portion solubilized 
can act as an initiator for the reaction, which is clearly improbable for the other portions. On the other hand, it is noticeable the good performance of nanometric $\mathrm{CaO}$ at $70{ }^{\circ} \mathrm{C}$ and $\mathrm{ZnO}$ at $150{ }^{\circ} \mathrm{C}$, which may support future investigations regarding those materials.

\section{CONCLUSION}

This paper shows a comparison between different nanostructured oxides, obtained by polymeric precursor method, regarding their activity for biodiesel conversion from oil-methanol mixtures. The temperature dependence for the heterogeneous catalysts was analyzed, where only $\mathrm{CaO}$ showed activities at $70{ }^{\circ} \mathrm{C}$ ( $\sim 98 \%$ of conversion), while the other oxides, $\mathrm{SnO}_{2}, \mathrm{ZnO}, \mathrm{TiO}_{2}, \mathrm{CaTiO}_{3}$, were observed active only at $150{ }^{\circ} \mathrm{C}$. Surface basicity against SA measurements revealed that the highest activity observed is not associated to SA only but mainly with the surface basicity. These results suggest that, for oxides synthesized by the polymeric precursor method, the surface basicity surpasses the particle size effects in catalysis in a way to promote the transesterification reaction.

\section{REFERENCES}

1. X. Lang, A.K. Dalai, N.N. Bakhshi, M.J. Reaney, and P.B. Hertz: Preparation and characterization of bio-diesels from various bio-oils. Bioresour. Technol. 80, 53 (2001).

2. M. Di Serio, R. Tesser, L. Pengmei, and E. Santacesaria: Heterogeneous catalysts for biodiesel production. Energy Fuels 22, 207 (2008).

3. X. Liu, X. Piao, Y. Wang, S. Zhu, and H. He: Calcium methoxide as a solid base catalyst for the transesterification of soybean oil to biodiesel with methanol. Fuel 87, 1076 (2008).

4. M.L. Granados, M.D.Z. Poves, D.M. Alonso, R. Mariscal, F.C. Galisteo, R. Moreno-Tost, J. Santamaría, and J.L.G. Fierro: Biodiesel from sunflower oil by using activated calcium oxide. Appl. Catal., B 73, 317 (2007).

5. R.M. Almeida, L.K. Noda, N.S. Gonçalves, S.M.P. Meneghetti, and M.R. Meneghetti: Transesterification reaction of vegetable oils, using superacid sulfated $\mathrm{TiO}_{2}$-base catalysts. Appl. Catal., A 347, 100 (2008).

6. A. Kawashima, K. Matsubara, and K. Honda: Development of heterogeneous base catalysts for biodiesel production. Bioresour. Technol. 99, 3439 (2008).

7. X. Liu, H. He, Y. Wang, S. Zhu, and X. Piao: Transesterification of soybean oil to biodiesel using $\mathrm{CaO}$ as a solid base catalyst. Fuel 87, 216 (2008).

8. S.J. Yoo, H. Lee, B. Veriansyah, J. Kim, J.D. Kim, and Y.W. Lee: Synthesis of biodiesel from rapeseed oil using supercritical methanol with metal oxide catalysts. Bioresour. Technol. 101, 8686 (2010).

9. M.K. Lam, K.T. Lee, and A.R. Mohamed: Sulfated tin oxide as solid superacid catalyst for transesterification of waste cooking oil: An optimization study. Appl. Catal., B 93, 134 (2009).

10. M. Kouzu, T. Kasuno, M. Tajika, Y. Sugimoto, S. Yamanaka, and J. Hidaka: Calcium oxide as a solid base catalyst for transesterification of soybean oil and its application to biodiesel production. Fuel 87, 2798 (2008).

11. G.J. Suppes, M.A. Dasari, E.J. Doskocil, P.K. Mankidy, and M.J. Goff: Transesterification of soybean oil with zeolite and metal catalysts. Appl. Catal., A 257, 213 (2004).
12. M.C.G. Albuquerque, I.J. Urbistondo, J.S. González, J.M.M. Robles, R.M. Tost, E.R. Castellón, A.J. López, D.C.S. Azevedo, C.L. Cavalcante, Jr., and P.M. Torres: $\mathrm{CaO}$ supported on mesoporous silicas as basic catalysts for transesterification reactions. Appl. Catal., A 334, 35 (2008).

13. A. Kawashima, K. Matsubara, and K. Honda: Acceleration of catalytic activity of calcium oxide for biodiesel production. Bioresour. Technol. 100, 696 (2009).

14. S. Bancquart, C. Vanhove, Y. Pouilloux, and J. Barrault: Glycerol transesterification with methyl stearate over solid basic catalysts. I. Relationship between activity and basicity. Appl. Catal., A 218, 1-11 (2001).

15. S. Yan, S. Mohan, C. DiMaggio, M. Kim, K.Y.S. Ng, and S.O. Salley: Long term activity of modified $\mathrm{ZnO}$ nanoparticles for transesterification. Fuel 89, 2844 (2010).

16. M. Niederberger: Nonaqueous sol-gel routes to metal oxide nanoparticles. Acc. Chem. Res. 40, 793 (2007).

17. C. Ngamcharussrivichai, P. Totarat, and K. Bunyakiat: $\mathrm{Ca}$ and $\mathrm{Zn}$ mixed oxide as a heterogeneous base catalyst for transesterification of palm kernel oil. Appl. Catal., A 341, 77 (2008).

18. A.C.A. Rubio, J.S. González, J.M.M. Robles, R.M. Tost, D.M. Alonso, A.J. López, and P.M. Torres: Heterogeneous transesterification processes by using $\mathrm{CaO}$ supported on zinc oxide as basic catalysts. Catal. Today 149, 281 (2010).

19. B.B. Lakshmi, P.K. Dorhout, and C.R. Martin: Sol-gel template synthesis of semiconductor nanostructures. Chem. Mater. 9, 857 (1997).

20. B.S. Barros, R. Barbosa, N.R. Santos, T.S. Barros, and M.A. Souza: Synthesis and $\mathrm{x}$-ray diffraction characterization of nanocrystalline $\mathrm{ZnO}$ obtained by Pechini method. Inorg. Mater. 42, 1348 (2006).

21. L.S. Cavalcante, V.S. Marques, J.C. Sczancoski, M.T. Escote, M.R. Joya, J.A. Varela, M.R.M.C. Santos, P.S. Pizani, and E. Longo: Synthesis, structural refinement and optical behavior of $\mathrm{CaTiO}_{3}$ powders: A comparative study of processing in different furnaces. J. Chem. Eng. 143, 299 (2008).

22. A.R. Malagutti, H.A.J.L. Mourão, J.R. Garbin, and C. Ribeiro: Deposition of $\mathrm{TiO}_{2}$ and $\mathrm{Ag}: \mathrm{TiO}_{2}$ thin films by the polymeric precursor method and their application in the photodegradation of textile dyes. Appl. Catal., B 90, 205 (2009).

23. D.A. de Macedo, B. Cela, R.M. do Nascimento, A.E. Martinelli, D.M.A. Melo, A.A. Rabelo, and C.A. Paskocimas: Synthesis, processing and characterization of $\mathrm{ZrO}_{2}-8 \mathrm{Y}_{2} \mathrm{O}_{3}, \mathrm{ZrO}_{2}-8 \mathrm{CeO}_{2}$ and $\mathrm{La}_{0.78} \mathrm{Sr}_{0.22} \mathrm{MnO}_{3}$ powders. J. New Mater. Electrochem. Syst. 12 , 103 (2009).

24. M.P. Pechini: Method of preparing lead and alkaline titanates and niobates and coasting method using the same to form a capacitor. U.S. Patent No. 3330697, July 11, 1967.

25. M.L. Moreira, E.C. Paris, G.S. do Nascimento, V.M. Longo, J.R. Sambrano, V.R. Mastelaro, M.I.B. Bernardi, J. Andrés, J.A. Varela, and E. Longo: Structural and optical properties of $\mathrm{CaTiO}_{3}$ perovskite-based materials obtained by microwaveassisted hydrothermal synthesis: An experimental and theoretical insight. Acta Mater. 57, 5174 (2009).

26. E.C. Paris, J.W.M. Espinosa, S. de Lazaro, R.C. Lima, M.R. Joya, P.S. Pizani, E.R. Leite, A.G. Souza, J.A. Varela, and E. Longo: $\mathrm{Er}^{3+}$ as marker for order-disorder determination in the $\mathrm{PbTiO}_{3}$ system. Chem. Phys. 335, 7 (2007).

27. G.P. Mambrini, C. Ribeiro, and L.A. Colnago: Nuclear magnetic resonance spectroscopic analysis of ethyl ester yield in the transesterification of vegetable oil: an accurate method for a truly quantitative analysis. Magn. Reson. Chem. 50, 1 (2011).

28. A. Umar, C. Ribeiro, A. Al-Hajry, Y. Masuda, and Y.B. Hahn: Growth of highly c-axis-oriented $\mathrm{ZnO}$ nanorods on $\mathrm{ZnO}$ /glass substrate: Growth mechanism, structural, and optical properties. J. Phys. Chem. C 113, 14715 (2009). 
29. C.M. Ronconi, C. Ribeiro, L.O.S. Bulhoes, and E.C. Pereira: Insights for phase control in $\mathrm{TiO}_{2}$ nanoparticles from polymeric precursors method. J. Alloys Compd. 466, 435 (2008).

30. E.F. Aboelfetoh and R. Pietschnig: Preparation and catalytic performance of $\mathrm{Al}_{2} \mathrm{O}_{3}, \mathrm{TiO}_{2}$ and $\mathrm{SiO}_{2}$ supported vanadium based-catalysts for C-H activation. Catal. Lett. 127, 83 (2009).

31. L. Xuejun, H. Huayang, W. Yujun, Z. Shenlin, and P. Xianglan: Transesterification of soybean oil to biodiesel using $\mathrm{CaO}$ as a solid base catalyst. Fuel 87, 216 (2008).

32. M. Morgenstern, J. Cline, S. Meyer, and S. Cataldo: Determination of the kinetics of biodiesel production using proton nuclear magnetic resonance spectroscopy (H-1 NMR). Energy Fuels 20, 1350 (2006).

33. K.G. Georgogianni, M.G. Kontominas, P.J. Pomonis, D. Avlonitis, and V. Gergis: Conventional and in situ transesterification of sunflower seed oil for the production of biodiesel. Fuel Process. Technol. 89, 503 (2008).

34. G. Vicente, M. Martínez, and J. Aracil: Integrated biodiesel production: a comparison of different homogeneous catalysts systems. Bioresour. Technol. 92, 297 (2004).

35. S.K. Karmee and A. Chadha: Preparation of biodiesel from crude oil of Pongamia pinnata. Bioresour. Technol. 96, 1425 (2005).

36. A.K. Singh and S.D. Fernando: Transesterification of soybean oil using heterogeneous catalysts. Energy Fuels 22, 2067 (2008).

37. D.W. Lee, Y.M. Park, and K.W. Lee: Heterogeneous base catalysts for transesterification in biodiesel synthesis. Catal. Surv. Asia 13 63 (2009).

38. M.R. Hoffmann, S.T. Martin, W. Choi, and D.W. Bahnemann: Environmental applications of semiconductor photocatalysis. Chem. Rev. 95, 69 (1995). 